\title{
Experimental Fire Tower Studies on Mechanical Pressurization to Control Smoke Movement Caused by Fire Pressures
}

\author{
G. T. TAMURA \\ Institute for Research in Construction \\ National Research Council of Canada \\ Ottawa, Canada \\ J. H. KLOTE \\ Center for Fire Research \\ National Bureau of Standards \\ Gaithersburg, Maryland 20899, USA
}

ABSTRACT

In designing a mechanical smoke control system to protect escape routes, it is necessary to have finformation on the adverse pressure differences caused by the various mechanisms and on the level of mechanical pressurlzation needed to overcome them. This paper deals with pressure differences caused by both the buoyancy force and thermal expansion due to fire. The tests were conducted in the ten-storey experimental fire tower in conjunction with a project on smoke control technology for a fire safe elevator. The calculated values of adverse pressure differences across the elevator shaft walls caused by the buoyancy force agreed we11 with the measured values, for fire temperatures from 450 to $850^{\circ} \mathrm{C}$. Also, the minimum amounts of mechanical pressurization required for neutralization were equal to the adverse pressures caused by the buoyancy force. Those caused by thermal expansion due to the rapid temperature rise were determined with the outside wall vents closed and with them opened. The test results verified that adverse pressures caused by fire can be controlled by mechanical pressurization to prevent smoke contamination of protected spaces. The mechanical pressurization system should be operated as soon as possible as the purging time for a contaminated elevator shaft or lobby can be long.

\section{INTRODUCTION}

The performance requirement for most mechanical smoke control systems is to control pressures in a building so that smoke is prevented from entering escape routes, such as an elevator shaft or stairshaft. In designing such systems, a knowledge of the adverse pressure differences caused by the fire and other mechanisms is needed to determine the amount of pressurization or exhaust required to overcome them. The mechanisms that should be considered are the temperature effect of fire, stack action due to the difference in air temperature inside and outside a building, wind action, and the operation of mechanical ventilation systems. The maximum adverse pressure difference due to a combination of these mechanisms can then serve as a criterion for designing a smoke control system and for testing its performance in a building.

The adverse pressures caused by these mechanisms were investigated in the ten-storey experimental fire tower, as part of a joint project 
being conducted by the National Research Council of Canada and the National Bureau of Standards (USA) on developing smoke control technology for a fire safe elevator (1). This paper reports on the results of tests conducted to determine the adverse pressures caused by buoyancy and thermal expansion due to fire, and the amount of mechanical pressurization required to prevent smoke from entering the elevator shaft and elevator lobbies.

\section{TEMPERATURE EFFECT OF FIRE}

Heat generated by fire results in increased gas temperature. Assuming that a fire compartment leaks sufficiently to preclude an appreciable buildup of pressure, it follows from the gas law, that the gas volume increases approximately in proportion to its absolute temperature. The pressure developed by the outflowing gas depends on the leakage area and volume of the fire compartment and on the rate of temperature rise. When the fire temperature reaches a steady value, the gas is no longer expanding and the smoke moves out of the compartment by buoyancy force alone. With fire in one floor of a building, air flows in through leakage openings in the walls of the fire compartment at low levels and smoke flows out of the compartment at upper levels to adjacent areas. This paper deals with a fire in a compartment of one-storey helght, not in a large space such as an atrium. The pressure difference due to buoyancy between a fire compartment and its surroundings can be expressed by the following equation:

$$
\Delta P_{f}=g h\left(\rho_{i}-\rho_{f}\right)=g \rho_{f}\left(T_{f}-T_{i}\right) / T_{i}
$$

where

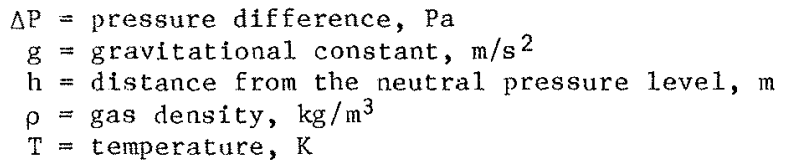

Subscripts

$i=$ outside the fire compartment

$\mathrm{f}=$ fire.

The level where the pressures of the fire compartment and the surrounding areas are equal is called the neutral pressure level (NPL). Above this level the pressures in the fire compartment are greater than those outside the compartment, resulting in gas flow out of the fire compartment; conversely, below this level air flows into the fire compartment. The location of the neutral pressure level depends on the vertical distribution and size of leakage openings and on the temperature of gases in the fire compartment and the surrounding area. It occurs on a level which results in a balance of mass flow into and out of the fire compartment.

DESCRIPTION OF THE EXPERIMENTAL FIRE TOWER

The fire tower (1) is part of the experimental facilities of the National Fire Laboratory of the Nationa1 Research Council of Canada, and 
is located about $60 \mathrm{~km}$ west of ot tawa. The plan view of a typical floor is shown in Figure 1. The experimental tower contains all the shafts and other features necessary to simulate the air and smoke movement patterns of a typical multi-storey building, including the elevator, stair, smoke exhaust, service, supply, and return air shafts. The exterior walls and the walls of vertical shafts are provided with variable openings that can be set to simulate the leakage areas of typical buildings. Two propane gas burner sets, each capable of producing heat at a rate of $2.5 \mathrm{MW}$, are located on the second floor burn area.

A separate structure adjacent to the tower houses the air moving and heating plant of the experimental tower; the air ducts run underground through a short tunnel to the bottom of the experimental fire tower. One system handles the main air supply and heating load and the other supplies outside air, either to the experimental stair and elevator shafts, or to vestibules interposed between the entrances to these shafts and the burn area.

Temperatures are measured in ten different locations on each floor using chrome-alumel thermocouples. Pressure differences across the various walls are measured using eighteen static pressure taps mounted flush to the walls on each floor. All pressure lines are connected to a 24-port pressure switch equipped with a diaphragm-type magnetic reluctance pressure transducer and located on the same floor in the observation area. Carbon dioxide concentrations are measured at six locations on each floor in the shafts, lobbles, corridors, and burn area by copper sampling tubes connected to a 12-port sampling switch unit with a nondispersive infrared gas analyzer. All devices of the three systems are controlled and monitored by a computer-based data acquistion and control system in the attached services unit.

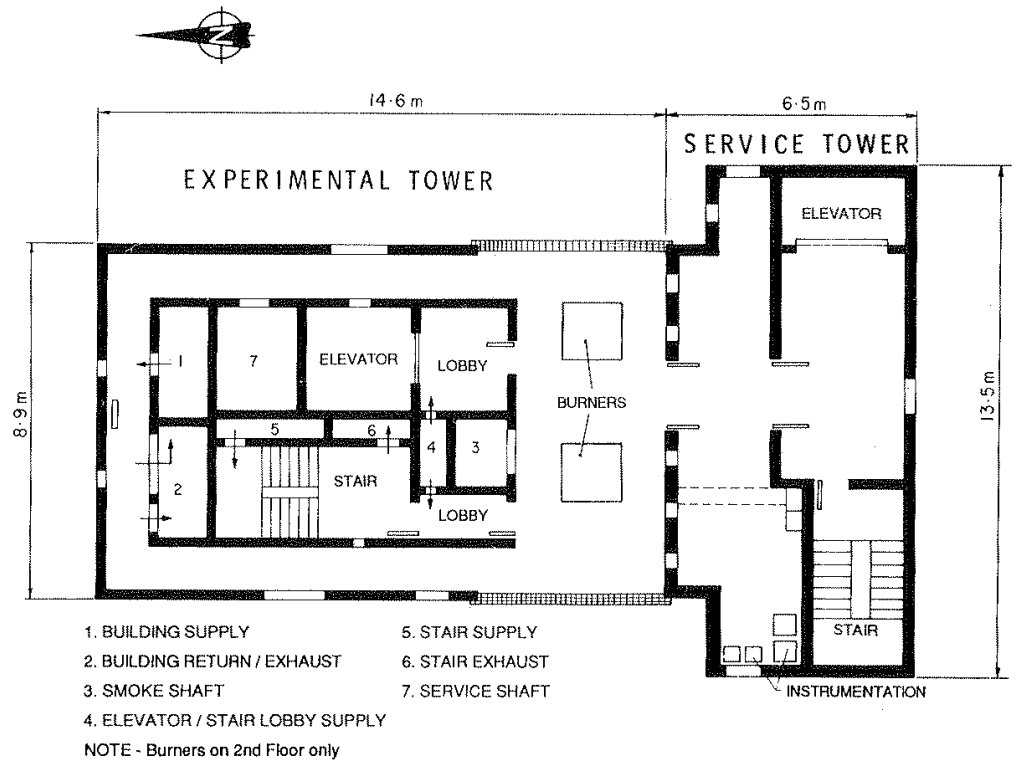

EIGURE 1. Plan of the experimental fire tower. 


\section{TEST PROCEDURE}

The leakage areas of the experimental fire tower were set for a building with average air tightness and an area per floor of $900 \mathrm{~m}^{2}$ or seven times that of the floor area of the experimental tower (1). They were based on measurements in several multi-storey buildings $(2,3)$.

The fire tests were conducted using the propane gas burner on the second floor nearest the elevator shaft (Figure 1) with the temperature near the ceiling above the burners to follow close to the ASTM-E119 standard time-temperature curve up to the maximum test temperatures and held constant thereafter. In addition to the pressures recorded throughout the tower with the data acquisition system, pressure differences across the elevator lobby wall on the door side at the 0.40 , 1.93 and $3.08 \mathrm{~m}$ levels of the second floor were recorded continuously with a pen recorder.

Five minutes after ignition, the east and west wall vents on the second floor, each with an area of $0.46 \mathrm{~m}^{2}$, were opened to simulate broken windows. Thirty minutes after ignition, the pressurization fan for the elevator shaft was activated and the supply air rate adjusted to neutralize the adverse pressure difference across the elevator lobby wall measured at the $3.08 \mathrm{~m}$ level on the fire floor (second floor). After the test, with the tower back to normal temperature, the elevator shaft was pressurized at the same supply air rate to record the pressure difference across the lobby wall at the same level. Six such burn tests were conducted at fire temperatures of $450,550,660,750$, and $840^{\circ} \mathrm{C}$. They were conducted with temperature differences between inside and outside the tower of less than $6^{\circ} \mathrm{K}$ and wind speed of less than $16 \mathrm{~km} / \mathrm{h}$.

To investigate the adverse pressures caused by thermal expansion, both the elevator lobby pressure difference at the $3.08 \mathrm{~m}$ leve1 and the burn temperature were recorded on a continuous pen recorder during the temperature rlse from the time of ignition of the gas burner. The measurements were repeated with two outside wall vents (total area of $0.93 \mathrm{~m}^{2}$ ) opened prior to igniting the burner.

Two fire tests were conducted at $750^{\circ} \mathrm{C}$ with the elevator shaft pressurized; in the first, the elevator shaft was pressurized before ignition and in the second, it was pressurized 50 minutes into the burn period. For both tests the elevator shaft was pressurized to obtain a pressure difference across the elevator lobby wall of $25 \mathrm{~Pa}$ under non-fire condition. The value of $25 \mathrm{~Pa}$ is often used in designing smoke control systems to combat fire pressures in buildings. Pressure differences, temperatures, and $\mathrm{CO}_{2}$ concentrations were measured throughout the tower during the tests.

\section{RESULTS AND OISCUSSTON}

\section{Buoyancy Force}

Pressure differences across the walls of the elevator lobby and the elevator shaft at the $3.08 \mathrm{~m}$ level on the fire floor (second floor) both referenced to the burn area pressure for fire temperatures from 450 to $840^{\circ} \mathrm{C}$ are shown in Figure 2. They varied from 9 to $14 \mathrm{~Pa}$ for the elevator shaft wall and from 5 to $7 \mathrm{~Pa}$ for the elevator lobby wall. The differences were smaller for the lobby wall because the elevator wall 


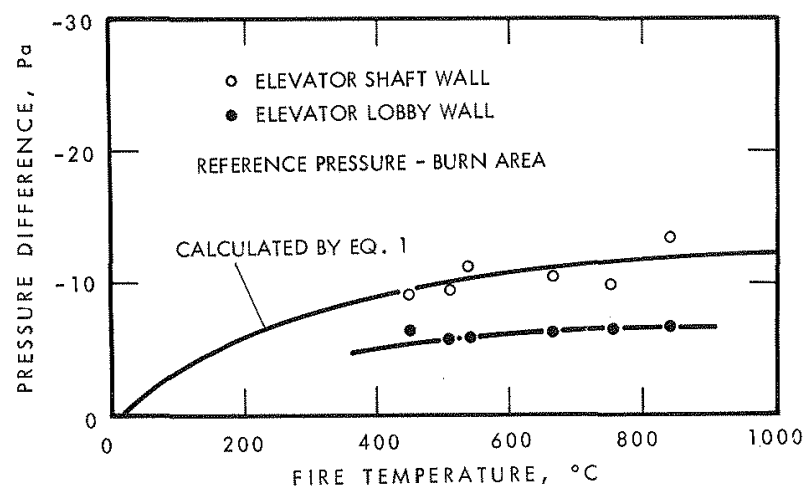

FIGURE 2. Pressure difference across elevator shaft wall and elevator lobby wall for various fire temperatures (pressure differences measured $3.08 \mathrm{~m}$ above $2 \mathrm{nd}$ floor level).

containing the elevator door provided additional resistance to gas flow from the burn area to the elevator shaft, and because the temperature was higher $\left(54^{\circ} \mathrm{C}\right)$ in the lobby than in the shaft $\left(23^{\circ} \mathrm{C}\right)$. The neutral pressure levels were located at about $1.7 \mathrm{~m}$ above floor level based on the pressure difference measurements on the door side of the elevator lobby wall. Using this value, pressure differences across the elevator shaft wall were calculated using Equation 1; they agreed reasonably we 11 with the measured values, as shown in Figure 2.

The maximum measured value was $14 \mathrm{~Pa}$. Fang (4) has measured pressures caused by room fires during a series of full-scale tests in a room with an open doorway and a celling height of $2.4 \mathrm{~m}$. The maximum pressure difference reached was $15 \mathrm{~Pa}$, across the burn room wall at the cetling, measured shortly after flashover. DeCicco (5) reported adverse pressure differences in the order of 10 to $15 \mathrm{~Pa}$ and a sharp peak of 35 Pa four minutes after ignition from a full scale fire test in a room with a floor height of $3.5 \mathrm{~m}$ in a multi-storey building. Butcher et al. (6) reported an adverse pressure difference of $5 \mathrm{~Pa}$ at the top of a stair door with a wood crib fire at $1000^{\circ} \mathrm{C}$. About $15 \mathrm{~Pa}$ appears to be the expected fire pressure due to buoyancy for ceiling heights up to $3.5 \mathrm{~m}$. As the fire pressure varies directly with the distance from the neutral pressure level (Eq. 1), higher pressures can be expected for floors of greater celling height.

During each fire test the elevator shaft was pressurized to neutralize the adverse pressure difference across the elevator lobby wall at the $3.08 \mathrm{~m}$ level. Figure 3 shows the vertical pressure difference profile with the fire temperature at $750^{\circ} \mathrm{C}$. Without pressurization the neutral pressure level was located at the $1.7 \mathrm{~m}$ level; with pressurization it was raised to the $3.08 \mathrm{~m}$ level, with an accompanying shift in the pressure profile to the right in the area of positive pressures.

The supply air rates for pressurization required to neutralize the adverse pressures for the range of fire temperatures tested were from 800 to $900 \mathrm{~L} / \mathrm{s}$ for the test elevator shaft. When the elevator shaft was 
FIRE TEMPERATURE, $750^{\circ} \mathrm{C}$

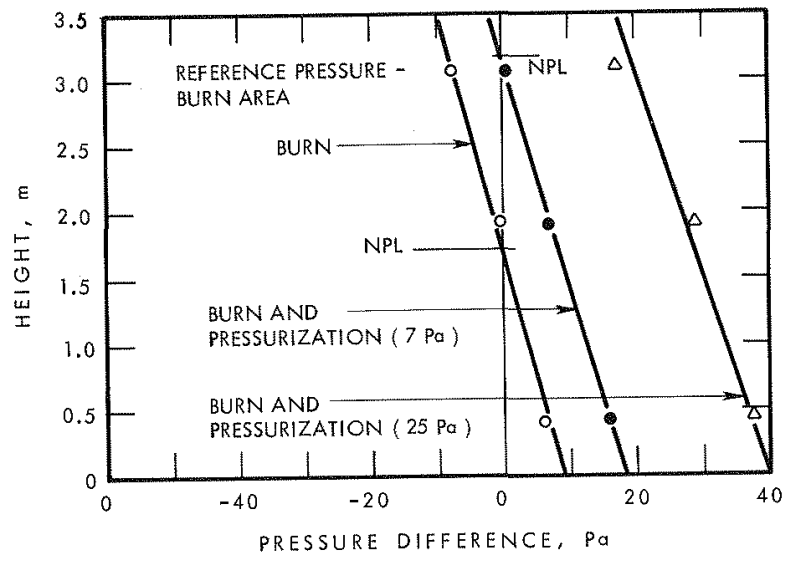

FIGURE 3. Pressure difference across the walls of the second floor elevator lobby during fire test with elevator shaft pressurization.

pressurized with these supply air rates and with the tower back to normal temperature, the amounts of pressurization were found to be about equal to the pressure differences caused by the fire. The pressurization required to prevent smoke infiltration, therefore, would be equal to the adverse pressure caused by the fire. The tests demonstrated that it is appropriate to use the adverse pressure difference due to fire as a component of the maximum required pressure difference as recommended in the ASHRAE Design Manua1. (7).

Thermal Expansion

The pressure differences shown in Figures 2 and 3 are those for fire temperature at a quasi-steady state. At ignition of the gas burner, as shown in Figure 4, the pressure difference increased instantaneously to a peak of $31 \mathrm{~Pa}$. Immediately thereafter, it dropped sharply to $16 \mathrm{~Pa}$ and gradually decreased to $6 \mathrm{~Pa}$ when the temperature stabilized at $600^{\circ} \mathrm{C}$. The cross-hatched area in Figure 4, which was obtained by subtracting the pressure differences due to buoyancy force from the measured pressure differences, represents the pressure differences due to thermal expansion. The test was repeated with the two outside wall vents (a total area of $0.93 \mathrm{~m}^{2}$ ) opened before ignition of the burner. As seen in Figure 5, a sharp peak of $8 \mathrm{~Pa}$ occurred at ignition, followed by a pressure increase to a maximum pressure difference of $9 \mathrm{~Pa}$ at $0.9 \mathrm{~min}$ after ignition; after that it decreased gradually to $7 \mathrm{~Pa}$ when the temperature reached $520^{\circ} \mathrm{C}$.

The area of opening in the fire floor enclosure has a significant influence on the effect of thermal expansion. The openings in the fire compartment affect the amount of pressure developed in the fire floor and the rate of temperature rise which, in turn, affects the rate of gas expansion. For buildings of typical construction, it is unlikely that the peak pressure difference caused by thermal expansion, because of its short duration, can seriously affect the performance of a smoke control system. However, it can be substantial for a relatively airtight 


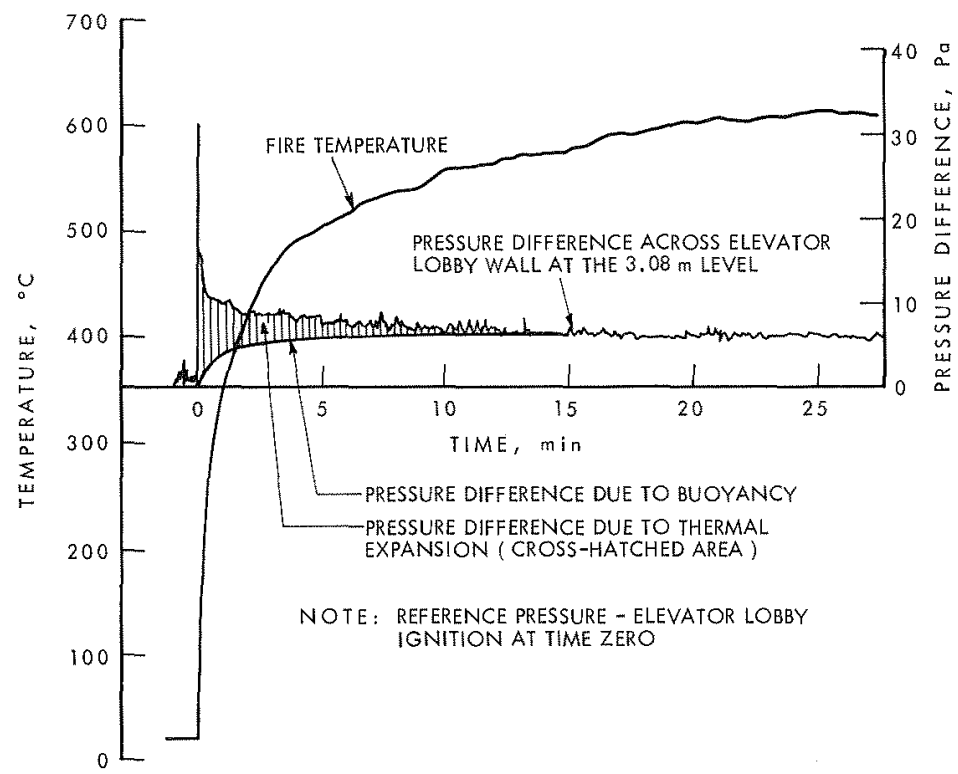

EIGURE 4. Pressure difference across elevator lobby wall and fire temperature vs time - outside wall vents closed.

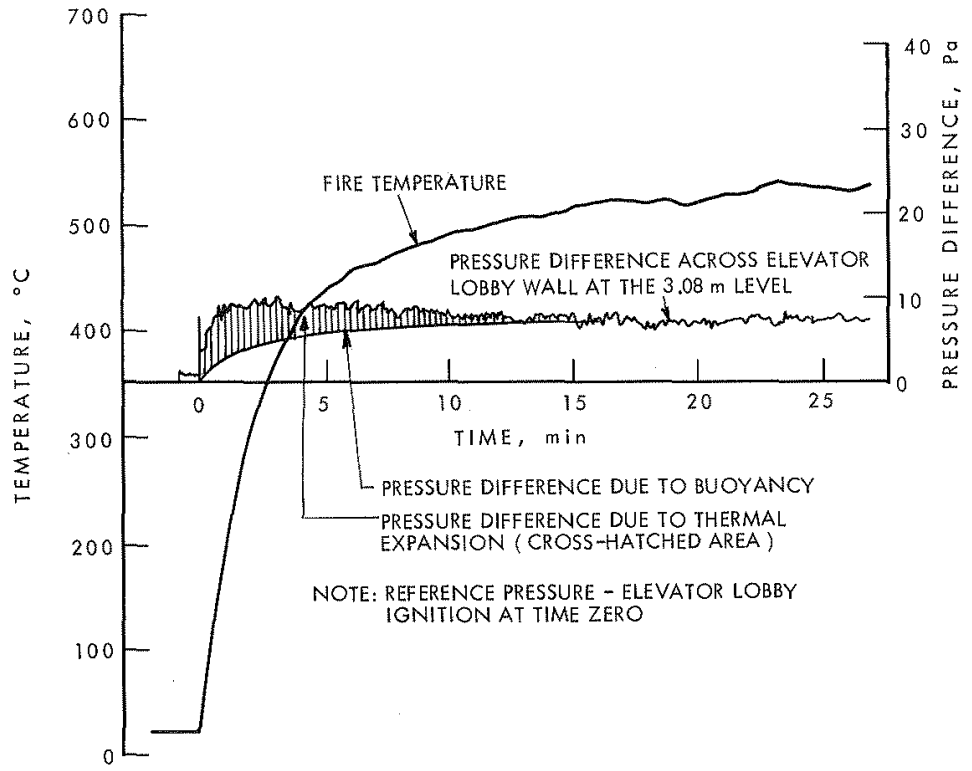

FIGURE 5. Pressure difference across elevator lobby wall and fire temperature vs time - outside wall vents open. 
compartment such as a bank vault or a ship compartment; pressure relief vents should be provided for such cases.

\section{Elevator Shaft Pressurization and Smoke Concentrations}

The vertical profile of pressure difference across the elevator lobby wall during the burn period with pressurization is shown in Figure 3. The required outside supply air rate for pressurization was $1880 \mathrm{~L} / \mathrm{s}$. The concentrations of $\mathrm{CO}_{2}$ as surrogate indicator of smoke can be expressed as percentage of concentration in the fire floor (second floor) measured $0.3 \mathrm{~m}$ below the ceiling in the burn area. Although a detailed hazard analysis is beyond the scope of this paper, a simplified approach to the smoke obscuration problem assumes that particulate concentrations from a solid fuel fire would be proportional to the $\mathrm{CO}_{2}$ concentrations measured from these tests. From a consideration of smoke obscuration, an area is assumed to be reasonably safe if it is not contaminated to an extent greater than $1 \%$ of that in the vicinity of a fire area (8). This assumption is probably conservative, in that smoke deposition reduces particulate concentration.

The $\mathrm{CO}_{2}$ concentration in the burn area was $5.2 \%$. Without mechanical pressurization, the $\mathrm{CO}_{2}$ concentrations (expressed in percent concentration of that in the burn area) were we11 above the $1 \%$ leve 1 in a11 spaces except the ground floor elevator lobby. Examination of the flow pattern as inferred from the pressure difference readings indicated that the combustion products spread from the burn area into the leakage openings in the walls of all vertical shafts and the ceiling of the second floor. When the elevator shaft pressurization system was activated prior to ignition, the elevator shaft and lobbies were maintained smoke free during the burn period. When it was activated during the burn period, the elevator shaft was cleared of $\mathrm{CO}_{2}$ in a short time but the levels of $\mathrm{CO}_{2}$ in the elevator lobbies, though much reduced, were still above the critical level. This indicated that the pressurization system should be activated before the elevator shaft and lobbies are heavily contaminated with smoke.

Although the tests were conducted in the ten-storey tower, the results are generally applicable to multi-storey buildings with typical leakage characteristics, as far as smoke movement due to fire pressures are concerned. Smoke movement due to wind and stack action was minimized by condacting tests under conditions of low wind and low inside-to-outside temperature difference.

\section{CONCLUSTON}

1. The equation for calculating pressure differences due to the buoyancy force agreed reasonably wel1 with the measured values at steady-state for the range of fire temperature from 450 to $840^{\circ} \mathrm{C}$. The maximum adverse pressure difference was about 14 Pa for the elevator shaft wall and $7 \mathrm{~Pa}$ for the elevator lobby wall. The pressure difference due to thermal expansion can be substantial, but because of its short duration, it is unlikely to seriously affect the performance of smoke control systems in buildings of average air tightness. During this short period a substantial amount of smoke and hot gas will flow into surrounding spaces if there is no pressurization to prevent it. With a large outside wall opening such as that caused by broken windows, the peak pressure difference due to thermal expansion is considerably 
less than without such openings. It should be cautioned that pressures due to thermal expansion can be substantial for relatively air-tight compartments.

2. The tests demonstrated that it is appropriate to use the adverse pressure difference due to the buoyancy force as a component of the minimum design pressure difference for designing smoke control systems for buildings.

3. The tests verified that adverse pressures caused by fire can be controlled by mechanical pressurization to prevent smoke contamination of elevators, so long as the required pressurization is maintained. The pressurization system should be operated as soon as possible, before the elevator shaft and lobbies are heavily contaminated with smoke, as the purging time can be long.

\section{ACKNOWLEDGEMENT}

The authors gratefully acknowledge the contribution of R.A. MacDonald in setting up and conducting the tests in the experimental fire tower and processing the test results; of J.E. Berndt in running the data acquisition and control system and the gas burner system; and of other staff members of the National Fire taboratory in assisting during the preparation and conduct of the tests. This paper is a contribution of the Institute for Research in Construction, National Research Council of Canada.

\section{REFERENCES}

1. Tamura, G.T. and Klote, J.H., "Experimental Fire Tower Studies on Elevator Pressurization Systems for Smoke Control". ASHRAE Transactions, V. 93, Part 2, 1987.

2. Tamura, G.T., and Shaw, C.Y., "Air Leakage Data for the Design of Elevator and Stair Shatt Pressurization Systems". ASHRAE Transactions, Vo1. 82, Part 2, pp. 179-180, 1976.

3. Tamura, G.T., and Shaw, C.Y., "Experimental Studies of Mechantcal Venting for Smoke Control in Tall office Buildings". ASHRAE Transactions, Vol. 84, Part 1, pp. 54-71, 1978.

4. Fang, J.B., "Static Pressures Produced by Room Fires". National Bureau of Standards, NBSIR 80-1984, February 1980.

5. DeCicco, P.R., "Smoke and Fire Control in High-Rise office Buildings - Part I: Full Scale Tests for Establishing Standards". Proceedings, Symposium on Experience and Applications on Smoke and Fire Contro1, ASHRAE, pp. 9-16, 1973.

6. Butcher, E.G., Farde11, P.J., and Clarke, J., "Pressurization as a Means of Controliing the Movememnt of Smoke and Toxic Gases on Escape Routes". Proceedings, JFRO Symposium No. 4, Movement of Smoke on Escape Routes in Buildings, Paper 5, Watford, 1969.

7. Klote, J.H., and Fothergi11, J.W., "Design of Smoke Control Systems For Buildings". American Society of Heating, Refrigerating and Air Conditioning Engineers, Inc., Atlanta, September 1983.

8. McGuire, J.H., Tamura, G.T., and Wilson, A.G., "Factors in Controlling Smoke in High Buildings". Proceedings, Symposium on Fire Hazards in Buildings, ASHRAE, pp. 8-13, 1970. 
